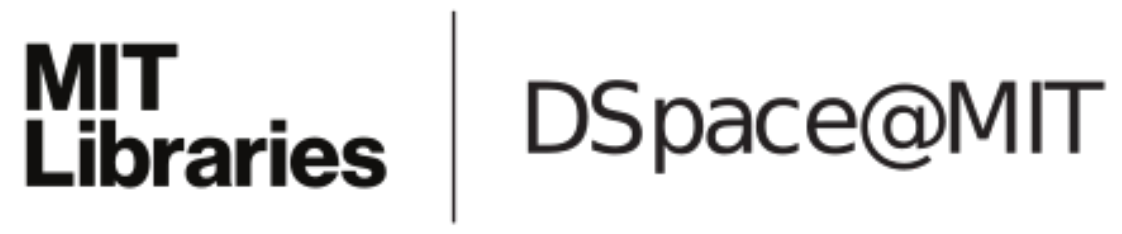

\author{
MIT Open Access Articles
}

Graphene Oxide as an Electrophile for Carbon Nucleophiles

The MIT Faculty has made this article openly available. Please share how this access benefits you. Your story matters.

Citation: Collins, William R., Ezequiel Schmois, and Timothy M. Swager. “Graphene Oxide as an Electrophile for Carbon Nucleophiles." Chemical Communications 47.31 (2011): 8790.

As Published: http://dx.doi.org/10.1039/c1cc12829a

Publisher: Royal Society of Chemistry

Persistent URL: http://hdl.handle.net/1721.1/74528

Version: Author's final manuscript: final author's manuscript post peer review, without publisher's formatting or copy editing

Terms of use: Creative Commons Attribution-Noncommercial-Share Alike 3.0 


\section{RSCPublishing ChemComm}

\section{Graphene Oxide as an Electrophile for Carbon Nucleophiles}

\begin{tabular}{|c|c|}
\hline Journal: & ChemComm \\
\hline Manuscript ID: & CC-COM-05-2011-012829.R1 \\
\hline Article Type: & Communication \\
\hline $\begin{array}{r}\text { Date Submitted by the } \\
\text { Author: }\end{array}$ & $\mathrm{n} / \mathrm{a}$ \\
\hline Complete List of Authors: & $\begin{array}{l}\text { Collins, William; Massachusetts Institute of Technology, Chemistry } \\
\text { Schmois, Ezequiel; Massachusetts Institute of Technology, } \\
\text { Chemistry } \\
\text { Swager, Timothy; Massachusetts Institute of Technology, } \\
\text { Department of Chemistry }\end{array}$ \\
\hline
\end{tabular}




\title{
Graphene Oxide as an Electrophile for Carbon Nucleophiles $\dagger$
}

\author{
William R. Collins, Ezequiel Schmois, and Timothy M. Swager* \\ Received (in $X X X, X X X) X$ th $X X X X X X X X X 20 X X$, Accepted Xth $X X X X X X X X X 20 X X$ \\ DOI: 10.1039/b000000x
}

\begin{abstract}
5 The covalent, surface functionalization of graphene oxide with the malononitrile anion has been demonstrated. Once installed, these surface-bound "molecular lynchpins" can be chemically modified to increase the solubility of the graphene derivative in either organic or aqueous environments.
\end{abstract}

${ }_{10}$ Graphene oxide (GO), an oxidatively derived and sonochemically exfoliated form of graphite, has been shown to be an excellent platform for the development of covalent surface- and edgefunctionalization methods. ${ }^{1}$ In particular, edge-based amidation ${ }^{2}$ and esterification reactions, ${ }^{3}$ as well as surface-based 15 carbamation, ${ }^{4}$ reduction, ${ }^{5}$ O-alkylation, ${ }^{6}$ and epoxide ringopening reactions ${ }^{7}$ on GO have generated a wide variety of chemically modified graphene derivatives with varying electronic, mechanical, and physicochemical attributes. Importantly, many of these graphene derivatives have been 20 incorporated into devices for potential industrial applications. ${ }^{8}$

Other than the chemical reduction of GO, the most widely utilized and most diverse surface functionalization reaction is the ring opening of epoxides with oxygen or nitrogen nucleophiles. ${ }^{1 \mathrm{a}}$ Unfortunately, due to the labile nature of carbon-oxygen and 25 carbon-nitrogen bonds on the surface of graphene, the newly installed functionality undergoes thermal-based removal at relatively low temperatures. ${ }^{6,7 b}$ Herein we directly address this problem and expand the scope of this transformation through the addition of carbon-based nucleophiles to functionalize the surface 30 of GO. ${ }^{9}$

In the initial stages of our investigation into this transformation we became acutely aware of the incompatibility of highly basic carbanion nucleophiles and GO. While the mechanism is not completely understood, it is known that under strongly alkaline 35 conditions GO is converted into reduced graphite oxide. ${ }^{10}$ It was therefore unsurprising when, under a variety of conditions, GO was rapidly transformed to a reduced graphitic material in the presence of organolithium or organocuprate reagents. Mechanistically, this side reaction was attributed to hydrolysis of 40 the carbanion by both the adsorbed water and the surface tertiary alcohols followed by a hydroxide-based deoxygenation of the GO starting material.

In an attempt to circumvent this undesirable process, the tertiary alcohol groups on GO were acetylated and the starting 45 material was extensively dried (see Supporting Information). Unfortunately, even under more stringently anhydrous conditions, the strongly basic organolithium and organocuprate reagents generated reduced graphitic material without any appreciable functional group incorporation.

50 Working under the hypothesis that the adsorbed water could not be completely removed from the surface of $\mathrm{GO}^{11}$ and that the highly basic carbanions were being deleteriously consumed before they could react with the epoxide functionality, watercompatible, anionic nucleophiles were investigated next. To this 55 end, the reaction of malononitrile with GO (Scheme 1) was chosen. This particular nucleophile was utilized for the following reasons: 1) the $\mathrm{pKa}$ of malononitrile is $11.1\left(\right.$ in $^{\left.\mathrm{H}_{2} \mathrm{O}\right)}{ }^{12}{ }^{12}$ ) nitriles possess an easily distinguishable FTIR stretching mode for qualitative analysis of the product, and 3) quantitative evaluation 60 of the reaction through nitrogen incorporation by X-ray photoelectron spectroscopy (XPS) was possible.

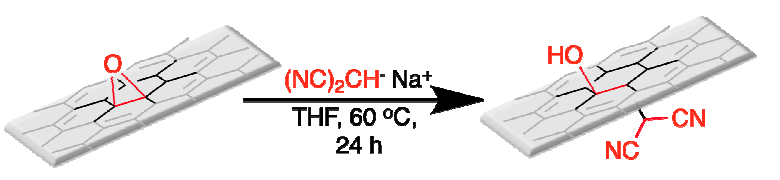

Graphite Oxide

Graphene Derivative

Scheme 1. Proposed addition of malononitrile anion to graphite 65 oxide (additional substrate oxygenation removed for clarity).

We began our study by mixing GO with the preformed sodium salt of malononitrile ( 1 equivalent per carbon on $\mathrm{GO}$, see Supporting Information) in THF at $60{ }^{\circ} \mathrm{C}$ for $24 \mathrm{~h}$. The brown 70 transparent solution quickly turned into a black opaque dispersion. After cooling the reaction mixture, the graphitic material could be isolated and purified through successive washings and centrifugations. FTIR analysis of the chemically modified graphene derivative (G1) identified the presence of a 75 new nitrile stretching frequency at $2194 \mathrm{~cm}^{-1}$, suggesting that a successful transformation had in fact occurred. ${ }^{13}$ Moreover, the $1250 \mathrm{~cm}^{-1}$ IR frequency associated with $\mathrm{C}-\mathrm{O}$ epoxide functionality was almost completely absent in the product (Figure $1)^{14}$

80 


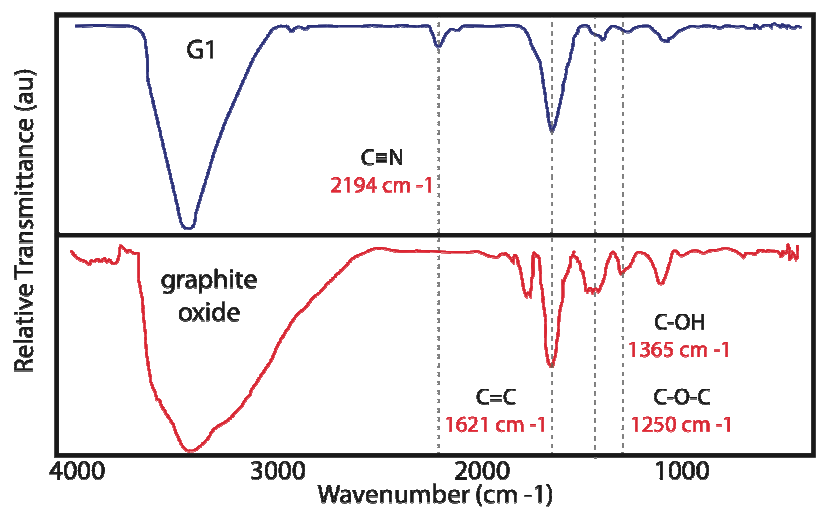

Figure 1. FTIR spectra of malononitrile functionalized graphene G1 (top), and graphite oxide (bottom).

Thermogravimetric analysis (TGA) of G1 showed a significant decrease in the $\mathrm{C}-\mathrm{O}$ functionality (epoxides and tertiary alcohols) as indicated by a smaller mass loss at $190-210{ }^{\circ} \mathrm{C}$ (as compared to GO). ${ }^{5 e, 15}$ This change was accompanied by a new thermal 10 decomposition at $480-510{ }^{\circ} \mathrm{C}$, which is proposed to arise from the newly formed carbon-bound malononitrile functional groups (Figure 2). The assignment of this mass change is in line with TGA thermograms of chemically modified graphene sheets with carbon-carbon bond surface functionality. ${ }^{9 b, c}$

15

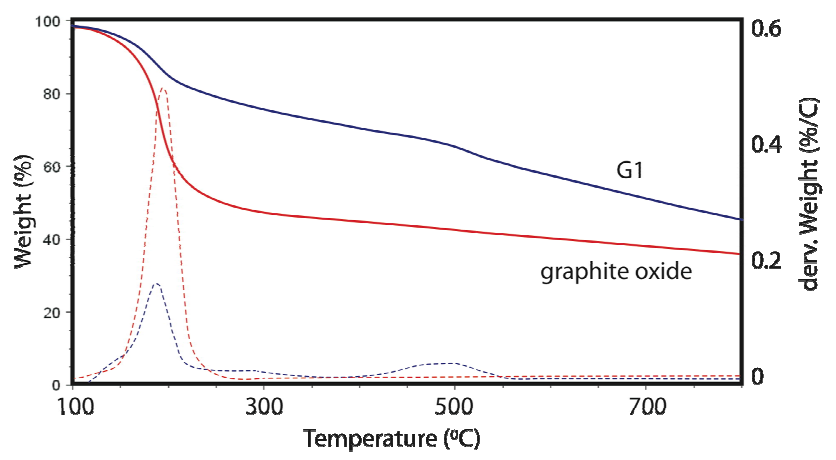

Figure 2. TGA and differential TGA thermograms of GO (red), and malononitrile functionalized graphene G1 (blue).

20 XPS elemental composition analysis confirmed that nitrogen incorporation had in fact occurred during the addition of malononitrile to GO (see Supporting Information for spectrum, atomic percentages, and functional group densities). Through integration of the high-resolution $\mathrm{N}(1 \mathrm{~s})$ signal at $398 \mathrm{eV}$, it could 25 be determined that $3.4 \%$ of G1 was nitrogen. Importantly, this $\mathrm{N}(1 \mathrm{~s})$ signal also precisely matched known XPS signals for alkyl nitrile functionality bound to the surface of activated carbon. ${ }^{16}$ Overall, this level of incorporation corresponds to a functional group density of 1 malononitrile per 46 graphene carbons.

30 The XPS spectrum (in agreement with the abovementioned TGA thermograms) also indicated that deoxygenation was occurring during the reaction. The atomic percentage for oxygen decreased from $27.7 \%$ to $15.1 \%$, which is an effective change in the $\mathrm{C} / \mathrm{O}$ ratio from 2.61 in $\mathrm{GO}$ to 5.40 in G1. It is possible to 35 rationalize this deoxygenation through both a thermal-based mechanism ${ }^{17}$ as well as a potentially competitive anionic-based reductive process. ${ }^{10}$

Additional qualitative evidence for the installation of surfacebound (and not edge-bound) malononitrile groups was obtained 40 through X-ray powder diffraction (XRD) pattern analysis of G1 (Figure 3). Specifically, the intersheet gallery distance increased from $0.84 \mathrm{~nm}$ in GO to $0.95 \mathrm{~nm}$ in the product. It is well known that deoxygenation of GO greatly reduces the intersheet gallery distance. ${ }^{5 \mathrm{c}}$ Therefore, a net increase in $\mathrm{d}$ spacing, despite a 45 reduction in surface oxygen functionality, requires that new functional groups now occupy the intersheet gallery. ${ }^{18}$

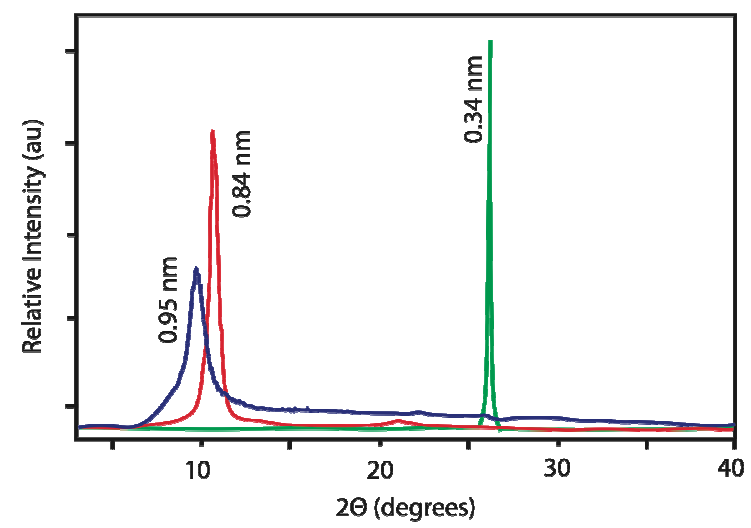

Figure 3. XRD patterns of graphite (green), graphite oxide (red), 50 and malononitrile functionalized graphene $\mathbf{G 1}$ (blue).

Four-point probe measurements were performed on thin films of $\mathbf{G 1}$ to determine whether enough deoxygenation had occurred to significantly re-establish conjugation within the graphene 55 sheets (see Supporting Information). As expected from the low C/O ratio of G1 very little conductivity was observed. Only through a subsequent thermal annealing of the thin films at 250 ${ }^{\circ} \mathrm{C}$ for $24 \mathrm{~h}$ (below the temperature at which the malononitrile groups eliminate) were moderate levels of conductivity observed ${ }_{60}(14.8 \mathrm{~S} / \mathrm{m}$ for G1). Interestingly, even after annealing the samples, the conductivity of $\mathbf{G 1}$ remained considerably lower than for chemically reduced graphene with a comparable $\mathrm{C} / \mathrm{O}$ ratio. ${ }^{5 c, 19}$ This difference is primarily attributed to the presence of covalently bound surface functionality that has a net disruptive ${ }_{65}$ effect on the conjugation of the graphene sheet.

Finally, to improve the solubility profile of $\mathbf{G 1}$ and to document the synthetic utility of this surface functionality, the malononitrile groups were subjected to a further anionic alkylation reaction. Thus, a solution of G1 in DMF was 70 deprotonated with $\mathrm{NaH}$ and then treated with either 1iodohexadecane or 1,3-propane sultone (see Supporting Information). After $16 \mathrm{~h}$ at room temperature, the reactions were quenched and the subsequent alkylated graphene derivatives G2 (hexadecane) and G3 (sulfonate) could be isolated and 75 characterized. Importantly, G2 (unlike the parent malononitrile graphene derivative G1) could now be easily dispersed into a variety of non-polar and polar organic solvents (see Supporting Information for solvent survey). Perhaps even more significantly, 
G3 now readily formed a stable dispersion in water (up to $\sim 1$ $\mathrm{mg} / \mathrm{mL}){ }^{20}$ As expected, in aqueous/organic biphasic systems, hexadecane functionalized $\mathbf{G 2}$ is immiscible in water and sulfonate functionalized G3 (zeta potential of $-47.1 \mathrm{mV}$, see ${ }_{5}$ Supporting Information) is immiscible in organic solvents (Figure 4).

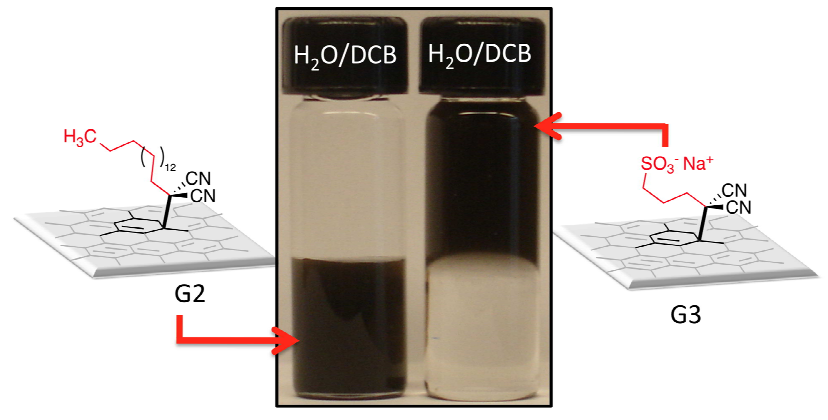

Figure 4. Solubility profile of $\mathbf{G 2}(1 \mathrm{mg} / \mathrm{mL}$, left vial) and $\mathbf{G 3}(1$ $10 \mathrm{mg} / \mathrm{mL}$, right vial) in dichlorobenzene $/ \mathrm{H}_{2} \mathrm{O}$ biphase (additional functionality removed for clarity in proposed structures).

In summary, the addition of a stabilized, carbanion nucleophile to GO has been demonstrated. Critical to the success of this 15 transformation was the need to reduce the basicity of the nucleophile below the pKa of water. To this end, malononitrile groups were efficiently installed on the surface of GO. These groups were, in turn, synthetically elaborated through an additional alkylation reaction. Current efforts are underway to 20 both install additional functionality on GO through this two-step method and to investigate potential applications for G1-G3 such as barrier materials, electrode constituents, and polymer composites.

Financial support for this work was provided by the IC ${ }_{25}$ Postdoctoral Fellowship Program. We are grateful for funding from the U.S. Army through the Institute for Soldier Nanotechnologies, under Contract W911NF-07-D-004 with the U.S. Army Research Office.

\section{Notes and references}

30 1. For reviews on the chemical functionalization of GO see: $(a) \mathrm{K}$. Loh, P. Bao, K. Ang, J. Yang, J. Mater. Chem. 2010, 20, 2277-2289; (b) O. C. Compton, S. T. Nguyen, Small, 2010, 6, 711-723; (c) D. Dreyer, S. Park, C. Bielawski, R. S. Ruoff, Chem. Soc. Rev. 2010, 39 228-240; (d) G. Cravotto, P. Cintas, Chem. Eur. J. 2010, 16, 52465259; (e) S. Park, R. S. Ruoff, Nat. Nanotech. 2009, 4, 217-224.

2. (a) S. Niyogi, E. Bekyarova, M. E. Itkis, J. L. McWilliams, M. A. Hamon, R. C. Haddon, J. Amer. Chem. Soc. 2006, 128, 7720-7721; (b) X. Zhang, Y. Huang, Y. Wan, Y. Ma, Z. Liu, Y. Chen, Carbon, 2008, 47, 343-347; (c) Y. Liu, J. Zhou, X. Zhang, Z. Liu, X. Wan, J.

40 Tian, T. Wang, Y. Chen, Carbon, 2009, 47, 3113-3121; (d) Y. Xu, Z. Liu, X. Zhang, Y. Wang, J. Tian, Y. Huang, Y. Ma, X. Zhang, Y. Chen, Adv. Mater. 2009, 21, 1275.

3. (a) D. Yu, Y. Yang, M. Durstock, J. Baek, L. Dai, ACS Nano, 2010, 4, 5633-5640; (b) L. Veca, F. Lu, M. Meziani, L. Cao, P. Zhang, G.

45 Qi, L. Qu, M. Shreshta, Y. Sun, Chem. Commun. 2009, 2565-2567; (c) H. Salavagione, M. Gomez, G. Martinez, Macromolecules, 2009, 42, 6331-6334.

4. (a) S. Stankovich, R. D. Piner, S. B. Nguyen, R. S. Ruoff, Carbon, 2006, 44, 3342; (b) C. Xu, X. Wu, J. Wu, X. Wang, Carbon, 2008, $50 \quad 46,365-389$.
5. (a) D. Li, M. B. Muller, S. Gilje, R. B. Kaner, G. G. Wallace, Nat. Nanotech. 2008, 3, 101-105; (b) W. Gao, L. B. Alemany, P. M. Ajayan, Nature Chem. 2009, 1, 403-408; (c) S. Park, J. An, R. D. Piner, S. Jin, X. Li, A. Velamakanne, R. S. Ruoff, Nano Lett. 2009, 9 , 55 1593-1597; (d) S. Stankovich, R. D. Piner, X. Chen, N. Wu, S. T. Nguyen, R. S. Ruoff, J. Mater. Chem. 2006, 16, 155-158; (e) S. Stankovich, D. A. Dikin, R. D. Piner, K. A. Kohlhaas, A. Kleinhammes, Y. Jia, Y. Wu, S. T. Nguyen, R. S. Ruoff, Carbon, 2007, 45, 1558-1565; (f) S. Dubin, S. Gilje, K. Wang, V. C. Tung, K.

60 Cha, A. S. Hall, R. Varshneya, Y. Yang, R. B. Kaner, ACS Nano, 2010, 4, 3845-3852.

6. J. Liu, Y. Wang, S. Xu, D. D. Sun, Mater. Lett. 2010, 64, 2236-2239.

7. (a) O. C. Compton, D. A. Dikin, K. W. Putz, L. C. Brinson, S. T. Nguyen, Adv. Mater. 2010, 22, 892-896; (b) R. Salvio, S.

65 Krabbenborg, W. J. Naber, A. H. Velders, D. N. Reinhoudt, W. G. Wiel, Chem. Eur. J. 2009, 15, 8235-8240; (c) H. Yang, F. Li, C. Shan, D. Han, Q. Zhang, L, Niu, A. Ivaska, J. Mater. Chem. 2009, 19, 4632-4638; (d) H. Yang, C. Shan, F. Li, D. Han, Q. Zhang, L. Niu, Chem. Commun. 2009, 3880; (e) S. Wang, P. J. Chia, L. Chua,

70 L. Zhao, R. Png, S. Sivaramakrishnan, M. Zhou, G. Goh, R. Friend, A. Wee, P. Ho, Adv. Mater. 2008, 20, 3440; $(f)$ S. Park, D. A. Dikin, S. T. Nguyen, R. S. Ruoff, J. Phys. Chem. C 2009, 113, 1580115804; ( $g$ ) L. Valentini, M. Cardinali, S. B. Bon, D. Bagnis, R. Verdejo, M. Lopez-Manchado, J. M. Kenny, J. Mater. Chem. 2010, 20, 995-1000.

8. (a) K. P. Loh, Q. Bao, G. Eda, M. Chhowalla, Nature Chem. 2010, 2, 1015-1024; (b) M. J. Allen, V. C. Tung, R. B. Kaner, Chem. Rev. 2010, 110, 132-145.

9. For examples of surface-based carbon-carbon bond forming reactions

80 on graphite or graphene see: (a) S. Chakraborty, J. Chattopadhyay, W. Guo, W. Billups, Angew. Chem. Int. Ed. 2007, 46, 4486-4488; (b) J. Lomeda, C. Doyle, D. Kosynkin, W. Hwang, J. Tour, J. Amer. Chem. Soc. 2008, 130, 16201-16206; (c) Z. Jin, J. Lomeda, B. Price, W. Lu, Y. Zhu, J. Tour, Chem. Mater. 2009, 21, 3045-3047; (d) X. Zhong, J. Jin, S. Li, Z. Niu, W. Hu, R. Li, J. Ma, Chem. Commun. 2010, 46, 7340-7342; (d) E. Bekyarova, M. Itkis, P. Ramesh, C. Berger, M. Sprinkle, W. de Heer, R. Haddon, J. Amer. Chem. Soc. 2009, 131, 1336-1337; (e) A. Sinitskii, A. Dimiev, D. Corley, A. Fursina, D. Kosynkin, J. Tour, ACS Nano, 2010, 4, 1949-1954; (f) S. Sarkar, E. Bekyarova, S. Niyogi, R. Haddon, J. Amer. Chem. Soc. 2011, 133, 3324-3327; (g) J. Englert, C. Dotzer, G. Yang, M. Schmid, C. Papp, J. Gottfried, H. Steinruck, E. Spiecker, F. Hauke, A. Hirsch, Nature Chem. 2011, 3, 279-286.

10. Two possible explanations for hydroxide-induced deoxygenation of GO are: (a) X. Fan, W. Peng, Y. Li, X. Li, S. Wang, G. Zhang, F. Zhang, Adv. Mater. 2008, 20, 4490-4493; (b) J. Rouke, P. Pandey, J. Moore, M. Bates, I. Kinloch, R. Young, N. Wilson, Angew. Chem. Int. Ed. 2011, 50, 1-6.

11. (a) D. A. Dinkin, S. Stankovich, E. J. Zimney, R. Piner, G. Dommett, G. Evmenenko, S. T. Nguyen, R. S. Ruoff, Nature, 2007, 448, 457460; (b) N. V. Medhekar, A. Ramasubramaniam, R. S. Ruoff, V. B. Shenoy, ACS Nano, 2010, 4, 2300-2306.

12. W. Matthews, J. Bares, J. Bartmess, F. Bordwell, F. Cornforth, G. Drucker, Z. Margolin, R. McCallum, G. McCollum, N. Vanier, J. Amer. Chem. Soc. 1975, 97, 7006-7014.

13. The nitrile stretching frequency for malononitrile is $2274 \mathrm{~cm}^{-1}$

14. (a) Y. Si, E. T. Samulski, Nano. Lett. 2008, 8, 1679-1682; (b) S. Park, K. S. Lee, G. Bozoklu, W. Cai, S. T. Nguyen, R. S. Ruoff, ACS Nano, 2008, 2, 572-578.

110 15. A. Lerf, H. Y. He, M. Forster, J. Klinowski, J. J. Phys. Chem. B, 1998, 102, 4477-4482.

16. R. J. Jansen, H. Bekkum, Carbon, 1995, 33, 1021-1027.

17. (a) M. J. McAllister, Chem. Mater. 2007, 19, 4396-4404; (b) W. Chen, L. Yan, P. R. Bangal, Carbon, 2010, 48, 1146-1152; (c) H. C. Scniepp, J. Li, M. J. McAllister, H. Sai, M. Herrera-Saville, D. H. Adamson, R. K. Prud-homme, J. Phys. Chem. B, 2006, 110, 85358539; (d) Y. Zhu, M. D. Stoller, W. Cai, A. Velamakanni, R. D. Piner, D. Chen, R. S. Ruoff, ACS Nano, 2010, 4, 1227-1233.

18. S. Stankovich, D. A. Dikin, O. C. Compton, G. H. Dommett, R. S. Ruoff, S. T. Nguyen, Chem. Mater. 2010, 22, 4153-4157. 
19. (a) H. Chen, M. B. Muller, K. J. Gilmore, C. G. Wallace, D. Li, Adv. Mater. 2008, 20, 3557-3561; (b) S. Park, J. An, R. D. Piner, I. Jung, D. Yang, A. Velamakanni, S. T. Nguyen, R. S. Ruoff, Chem. Mater. 2008, 20, 6592-6594

520 . For an example of surface bound sulfonate groups electrostatically stabilizing graphene sheets in an aqueous environment see ref. 14a.

Department of Chemistry, Massachusetts Institute of Technology,

Cambridge, MA, USA. E-mail: tswager@mit.edu

$15 \dagger$ Electronic Supplementary Information (ESI) available: Experimental and spectral data. See DOI: 10.1039/b000000x/ 


\title{
Graphene Oxide as an Electrophile for Carbon Nucleophiles
}

\author{
William R. Collins, Ezequiel Schmois, and Timothy M. Swager*
}

Department of Chemistry and Institute for Soldier Nanotechnologies, Massachusetts Institute of Technology, 77 Massachusetts Avenue, Cambridge, MA, 02139

General Experimental: Graphite powder was received from Alfa Aeser (natural, microcrystal grade, APS 2-15 micron, lot \#C04U006) and used without further purification. The reaction solvent THF (Fisher, spectroscopic grade) was dried by passage through two columns of neutral alumina in a solvent dispensing system. Sodium hydride (dry 95\%, Aldrich), malononitrile (Aldrich), acetyl chloride (Aldrich), 1-iodohexadecane (Aldrich), 1,3-propane sultone (Aldrich), methanol (Fisher, reagent grade), acetone (Aldrich, reagent grade), dichloromethane (Aldrich, reagent grade), dimethylformamide (Aldrich, reagent grade) and sodium bicarbonate (Fisher) were purchased from commercial sources and used as received. Graphite oxide ${ }^{1}$ was synthesized utilizing a slightly modified Hummer's oxidation procedure in which the sodium nitrate is excluded.

General Instrumentation: Fourier transform infrared (FT-IR) spectroscopy was performed on a Perkin-Elmar model 2000 FT-IR spectrophotometer using the Spectrum v. 2.00 software package. TGA analyses were performed with a TGA Q50 apparatus (TA instruments). TGA experiments were carried out under a nitrogen atmosphere. Samples were heated at $10{ }^{\circ} \mathrm{C} / \mathrm{min}$ from $50{ }^{\circ} \mathrm{C}$ to $800{ }^{\circ} \mathrm{C}$. The thickness of thin films was measured using a Dektak 6M stylus profiler by Vecco and their conductivities were measured utilizing a Signatone four point probe with a $1.27 \mathrm{~mm}$ spacing connected to a Keithley 2400 source meter. XPS spectra were recorded on a Kratos AXIS Ultra X-ray Photoelectron Spectrometer. XPS samples were prepared by drop-casting concentrated solutions of the graphene derivative onto silicon wafers. X-ray data was collected using an Inel CPS 120 position 
sensitive detector using an XRG 2000 generator $(\mathrm{Cu} \mathrm{Ka})$ and a Minco CT 137 temperature controller. XRD samples were prepared by dropcasting concentrated solutions of the graphene derivative onto silicon wafers. Zeta potential measurements and phase analysis light scattering measurements were determined with a Brookhaven instruments Zeta PALS, zeta potential analyzer. The zeta potential was taken as an average over 10 measurements [at $7.2 \mathrm{pH}$ ]. All synthetic manipulations were carried out under an argon atmosphere using standard Schlenk techniques.

Synthesis of acetylated graphite oxide: To a $100 \mathrm{~mL}$, sealable Schlenk tube fitted with a stirbar was added graphite oxide (200 mg, [XPS analysis: $72.3 \mathrm{C} / 27.7 \mathrm{O}])$, acetyl chloride (50 mL) and sodium bicarbonate $(100 \mathrm{mg})$. After sealing the pressure tube, the heterogeneous suspension was brought to 60 ${ }^{\circ} \mathrm{C}$ in an oil bath and heated for $24 \mathrm{~h}$. After cooling, this dispersion was quenched dropwise with a cold solution of satd. sodium bicarbonate in methanol. The dispersion was then centrifuged at 10,000 rpm for 10 minutes to obtain a black sediment. Sonicative dispersion with subsequent centrifugation was repeated 3 times with water, 2 times with methanol, 2 times with dichloromethane, and again 2 times with acetone. The supernatant was discarded each time. The final sediment was dried under high vacuum $(0.1 \mathrm{~mm} \mathrm{Hg})$ for $1 \mathrm{~h}$. See figure S1 for FT-IR characterization data.

\section{Synthesis of malononitrile-functionalized graphene derivatives (G1): To a $100 \mathrm{~mL}$ round bottom}

flask fitted with a stirbar and an argon inlet adaptor was added sodium hydride ( $82 \mathrm{mg}, 3.41 \mathrm{mmol})$ and THF (30 mL). The solution was then brought to $0{ }^{\circ} \mathrm{C}$ in an ice bath and the malononitrile $(220 \mathrm{mg}, 3.33$ mmol) was added in one portion. The mixture was stirred for 10 minutes. To another $100 \mathrm{~mL}$ round bottom flask fitted with a stirbar was added graphite oxide (40 mg, [XPS analysis: $72.3 \mathrm{C} / 27.7$ O]) and THF (10 mL). The heterogeneous suspension was sonicated for 30 minutes in a bath sonicator to achieve a homogenous dispersion. The malononitrile solution was then added dropwise to the graphite oxide suspension at room temperature. The combined reaction mixture was then brought to $60{ }^{\circ} \mathrm{C}$ in an oil bath for $24 \mathrm{~h}^{2}$ During the reaction timecourse the solution gradually darkened to an opaque black dispersion. After cooling, this dispersion was centrifuged at 10,000 rpm for 10 minutes to obtain a black sediment. Sonicative dispersion with subsequent centrifugation at 14,500 rpm was repeated 3 times with 
water, 2 times with methanol, and 2 times with acetone. The supernatant was discarded each time. The final sediment was dried under high vacuum $(0.1 \mathrm{~mm} \mathrm{Hg})$ for $1 \mathrm{~h}$. See figures S2-S6 and table S1 for FT-IR, XPS, high-resolution XPS, TGA, DTGA and XRD characterization data.

Synthesis of hexadecane/malononitrile-functionalized graphene derivatives (G2): ${ }^{3}$ To a $50 \mathrm{~mL}$ round bottom flask fitted with a stirbar and an argon inlet adaptor was added (1) (20 mg) and $2.5 \mathrm{~mL}$ anhydrous DMF. The black suspension was sonicated for 5 minutes to achieve a fine dispersion. To this suspension was added sodium hydride $(40 \mathrm{mg}, 1.66 \mathrm{mmol})$ and then 5minutes later 1-iodohexadecane (584 mg, $1.66 \mathrm{mmol})$ in one portion. The mixture was stirred for 16 hours at room temperature. To the reaction was then added $5 \mathrm{~mL}$ of water to quench the remaining $\mathrm{NaH}$. An additional $40 \mathrm{~mL}$ of water was then added and the hetereogeneous dispersion was then centrifuged at 10,000 rpm for 10 minutes to obtain a black/grey sediment. Sonicative dispersion with subsequent centrifugation at 5,000 rpm was repeated 3 times with water, 3 times with acetone, and 3 times with THF. The supernatant was discarded each time. The final black sediment was dried under high vacuum $(0.1 \mathrm{~mm} \mathrm{Hg})$ for $1 \mathrm{~h}$. See figure S7S9 for FT-IR, XPS and solubility characterization data.

\section{Synthesis of sulfonate/malononitrile-functionalized graphene derivatives $(\mathbf{G 3}):^{3}$ To a $50 \mathrm{~mL}$} round bottom flask fitted with a stirbar and an argon inlet adaptor was added (1) (20 mg) and $2.5 \mathrm{~mL}$ anhydrous DMF. The black suspension was sonicated for 5 minutes to achieve a fine dispersion. To this suspension was added sodium hydride $(40 \mathrm{mg}, 1.66 \mathrm{mmol})$ and then 5 hours later 1,3-propane sultone (202 mg, $1.66 \mathrm{mmol}$ ) in one portion. The mixture was stirred for 16 hours at room temperature. To the reaction was then added $5 \mathrm{~mL}$ of water to quench the remaining $\mathrm{NaH}$. An additional $40 \mathrm{~mL}$ of water was then added and the black homogeneous solution was then centrifuged at 14,500 rpm for $1 \mathrm{~h}$ to obtain a black sediment. The supernatant was carefully decanted and the remaining amount of water was removed by lyophilization for 24 h. Stable suspensions of $\mathbf{G 3}$ in $\mathrm{pH} 7$ water could be formed for up to $12 \mathrm{~h}$ before significant sedimentation occurred. See figure S10-S11 for FT-IR and XPS characterization data. 
General procedure for the determination of conductivities of (G1): A graphene derivative was sonicated in acetone for $30 \mathrm{~min}$. Subsequently, $100 \mu \mathrm{L}$ of the suspension was drop-cast onto a glass slide and air-dried to create a thin film. Using a four-point probe setup, the electric potential was measured at a current of 2,4, and $6 \mu \mathrm{A}$ for each film. The film was then annealed in a vacuum oven at $250{ }^{\circ} \mathrm{C}$ for $24 \mathrm{~h}$ and the electric potential was re-measured. Subsequently, the thickness of the film was measured using a profilometer and the conductivity was calculated using equation 1

$$
\sigma=I /(V \cdot t \cdot C F)(\text { for } \mathrm{t} / \mathrm{s}<0.4)
$$

where $\mathrm{I}$ is the current, $\mathrm{V}$ is the voltage, $\mathrm{t}$ is the sample thickness, $\mathrm{CF}$ is the sheet resistance correction factor, ${ }^{4}$ and $s$ is the four point probe spacing.

Conductivity of G1: The conductivity of a drop-cast film of malononitrile-functionalized graphene was determined to be $\sim 0.01 \mathrm{~S} \mathrm{~m}^{-1}$ (average of three films and four measurements each).

Conductivity of G1 (thermally treated): The conductivity of malononitrile -functionalized graphene annealed at $250{ }^{\circ} \mathrm{C}$ was determined to be $14.8 \mathrm{~S} \mathrm{~m}^{-1}$ (average of two films and three measurements each).

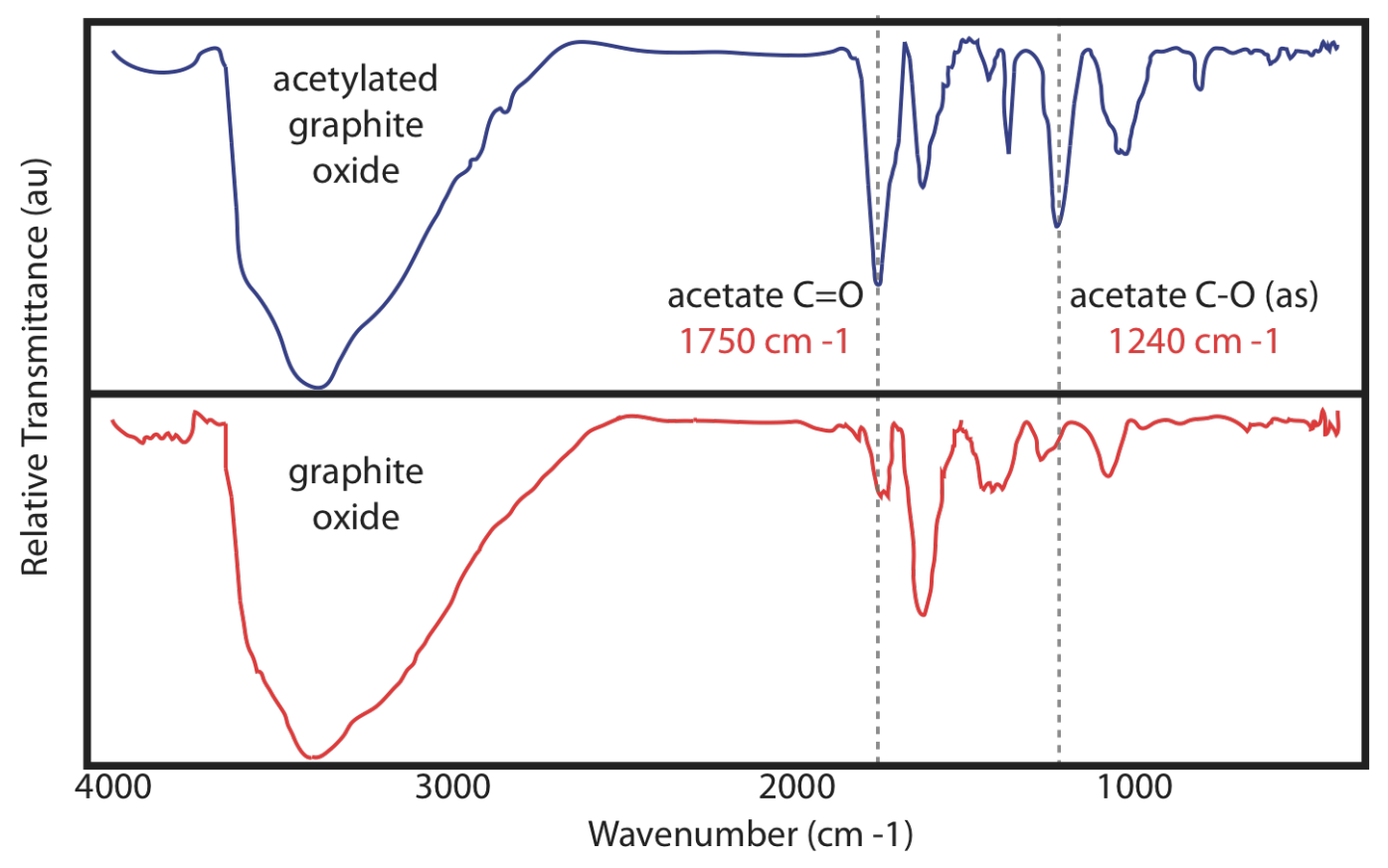

Figure S1. Baseline corrected FTIR of acetylated graphite oxide (blue) and graphite oxide (red) 


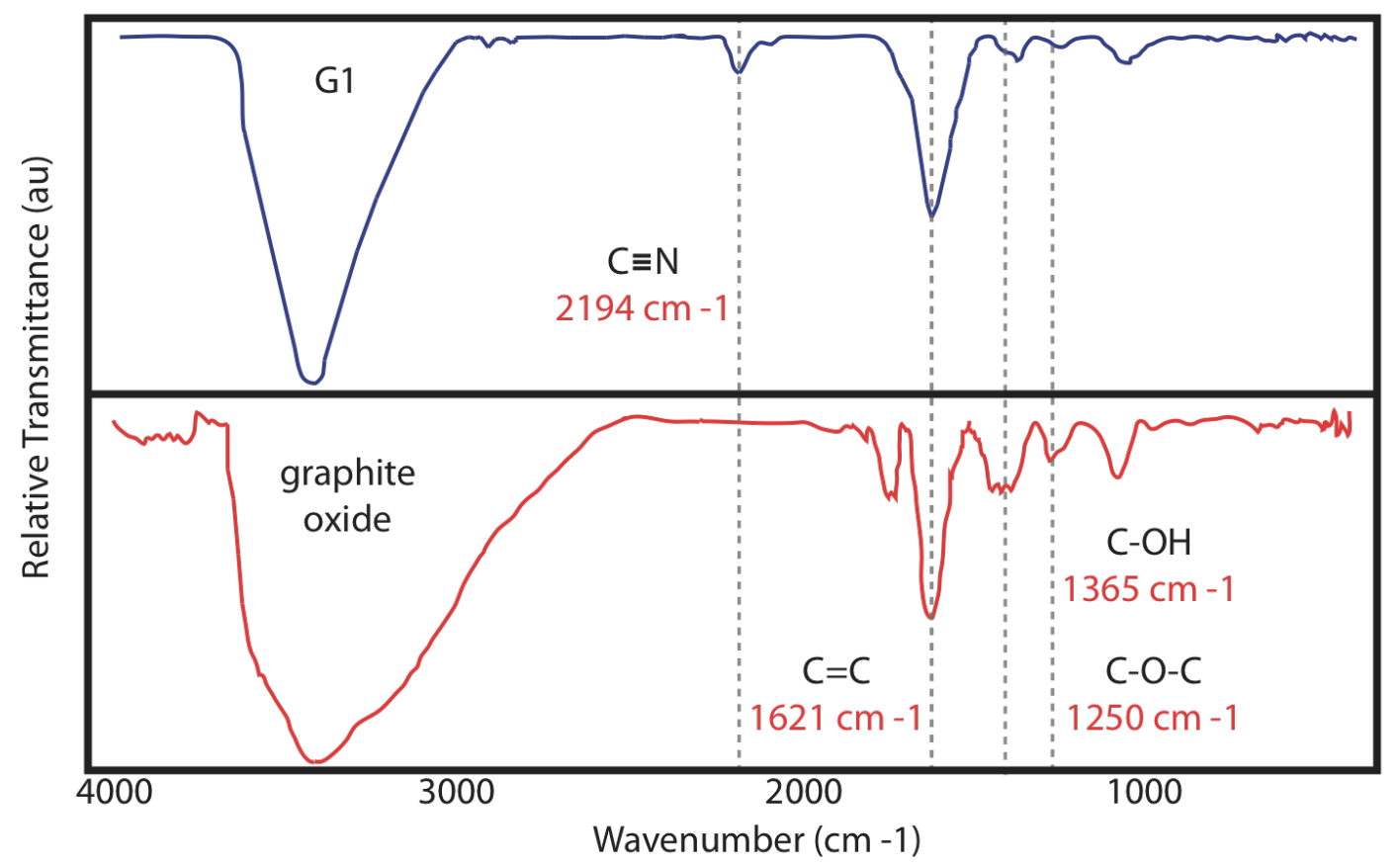

Figure S2. baseline corrected FT-IR spectra of graphite oxide (red) and malononitrile functionalized graphene (G1, blue)

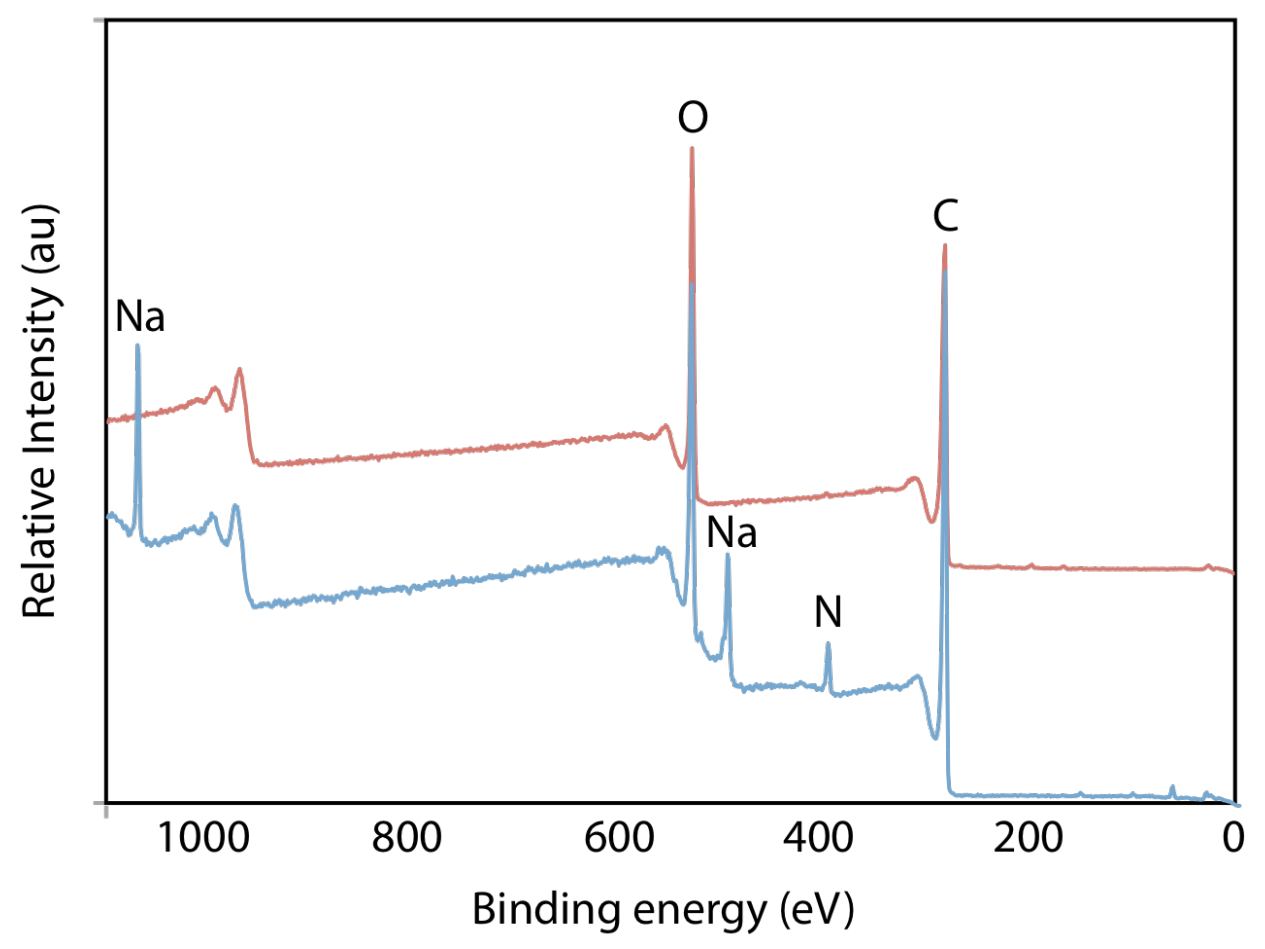

Figure S3. XPS survey spectrum of graphite oxide (red) and amide functionalized graphene $(\mathbf{G 1} \text {, blue })^{4}$ 
Table S1. Atomic composition of chemically modified graphite oxide (G1) by X-ray photoelectron spectroscopy ${ }^{5}$

\begin{tabular}{c|c|c|c|c}
\hline Peak & Position BE (eV) & Raw area (CPS) & Atomic Mass & Atomic Conc. \% \\
\hline C 1s & 284 & 1085251.9 & 12.011 & 81.52 \\
\hline O 1s & 531 & 797064.4 & 15.999 & 15.10 \\
\hline N 1s & 398 & 95545.0 & 14.007 & 3.38 \\
\hline
\end{tabular}

[a] Calculated by integration of diagnostic XPS signals. [b] Sensitivity factors: C(1s) 0.278, O(1s) $0.780, \mathrm{~N}(1 \mathrm{~s}) 0.477$

Atomic composition ratios:

- Functional group density of 1 malononitrile per 46 graphitic carbon calculated by: (([C\%][N\%])$1)^{*} 2$, wherein one carbon is removed due to its incorporation in the malononitrile structure, and the sum multiplied by 2 to account for 2 nitrogen atoms being incorporated for each malononitirile.

- $\mathrm{C} / \mathrm{O}$ ratio of 5.40 calculated by: $([\mathrm{C} \%] /[\mathrm{O} \%])$
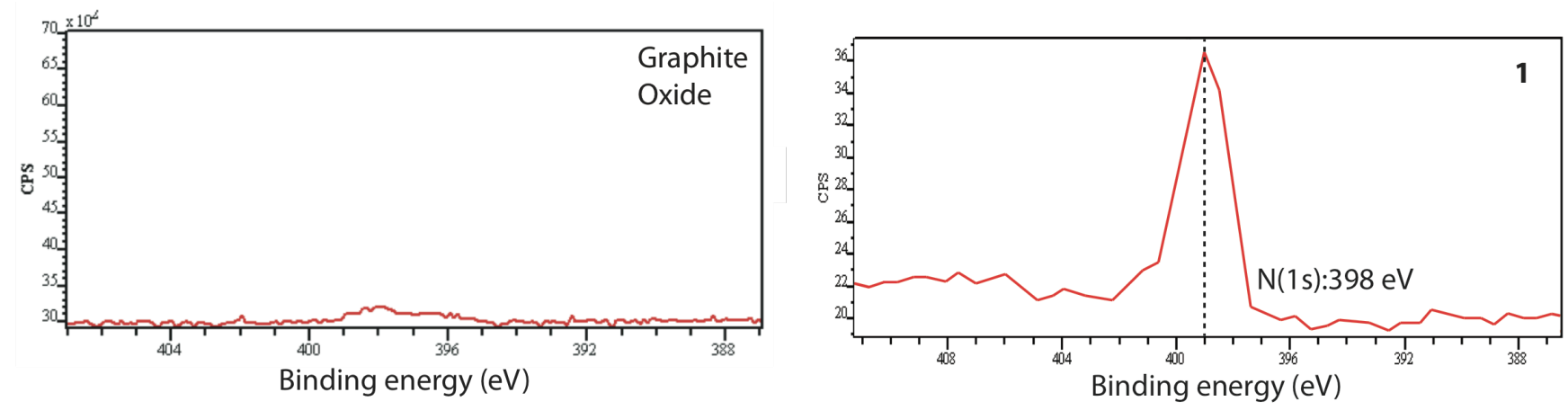

Figure S4. High-resolution XPS spectra of C(1s) and N(1s) regions of G1 and graphite oxide 


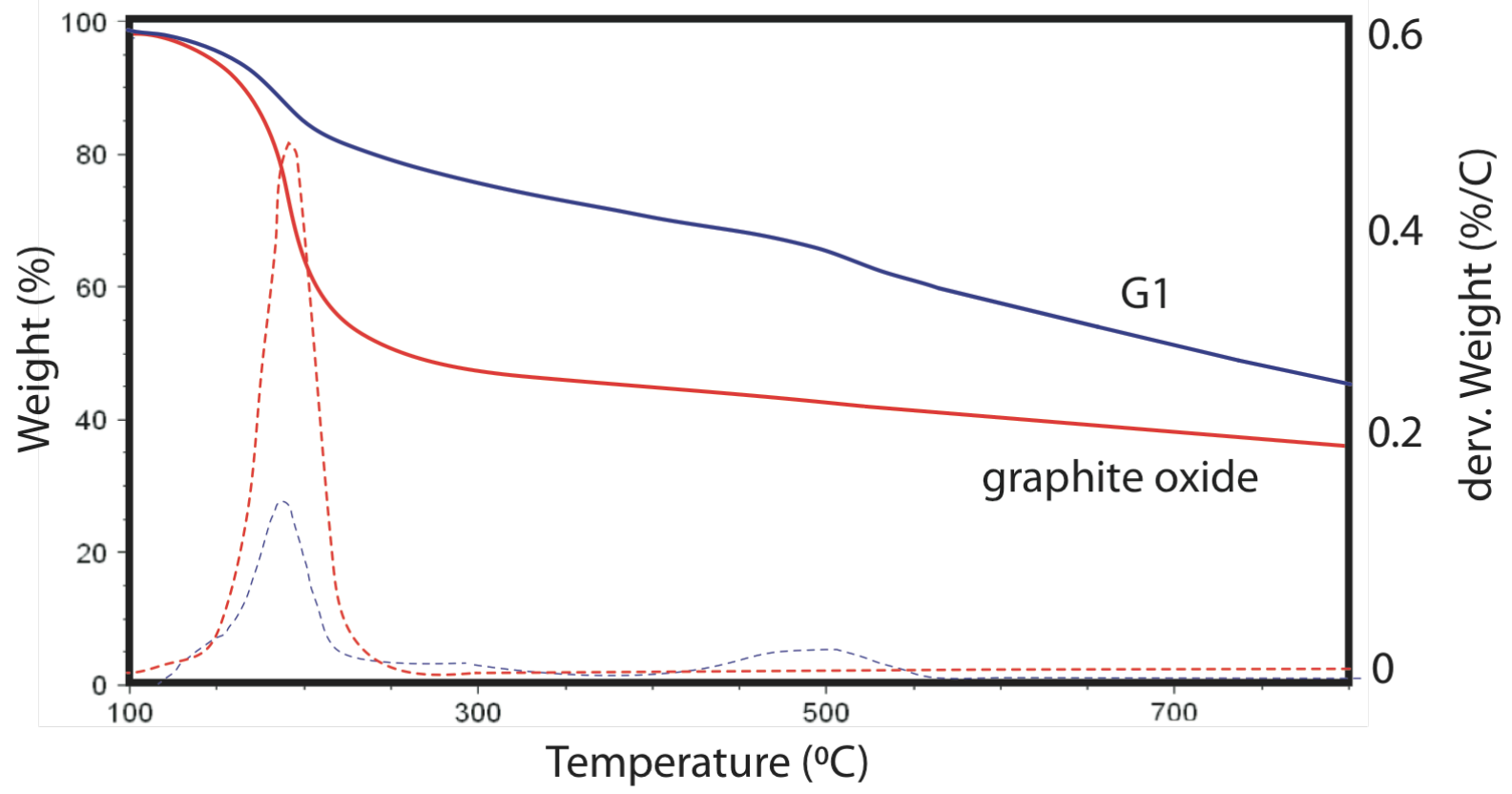

Figure S5. TGA and differential TGA thermograms of malononitrile functionalized graphene (G1, blue) and graphite oxide (red)

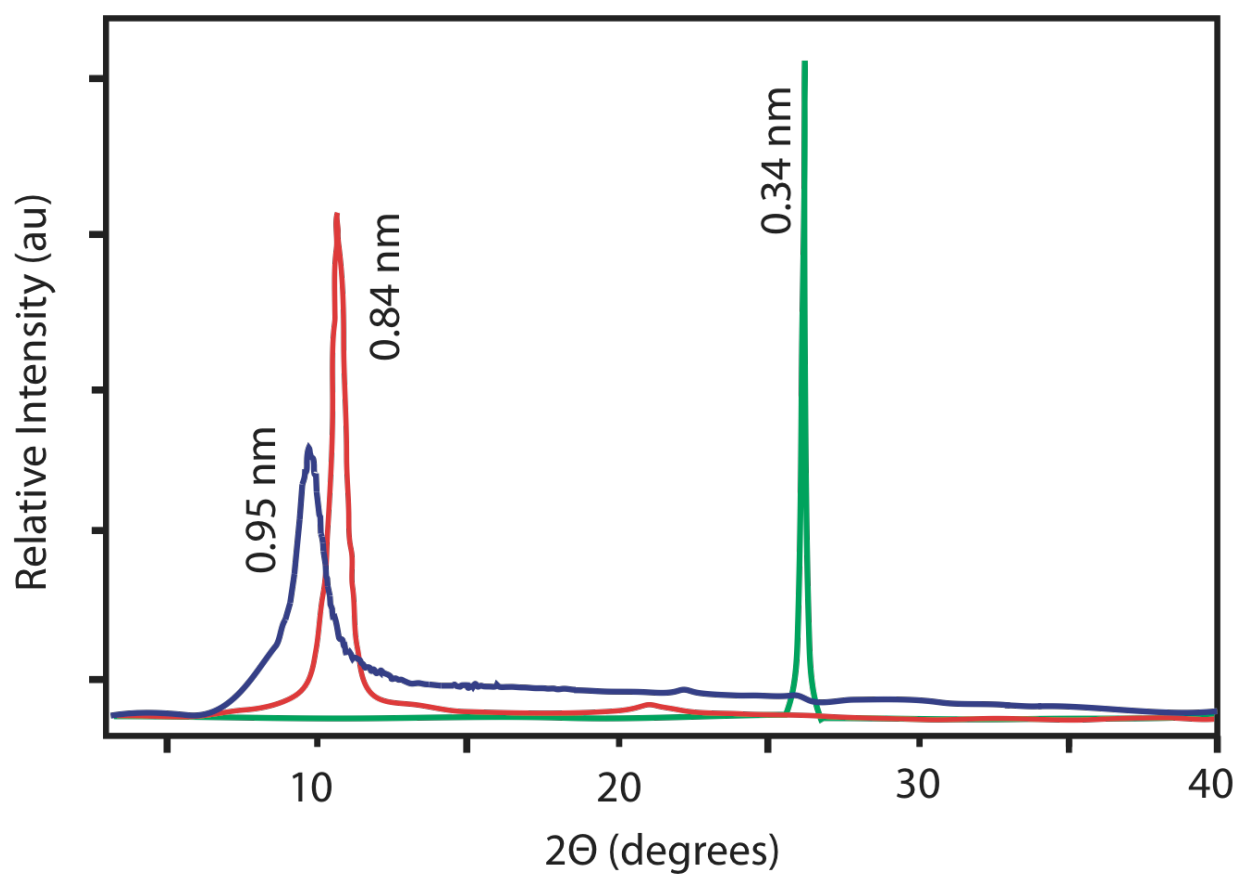

Figure S6. XRD patterns of malononitrile functionalized graphene (G1, blue), and graphite oxide (red), and graphite (green) 


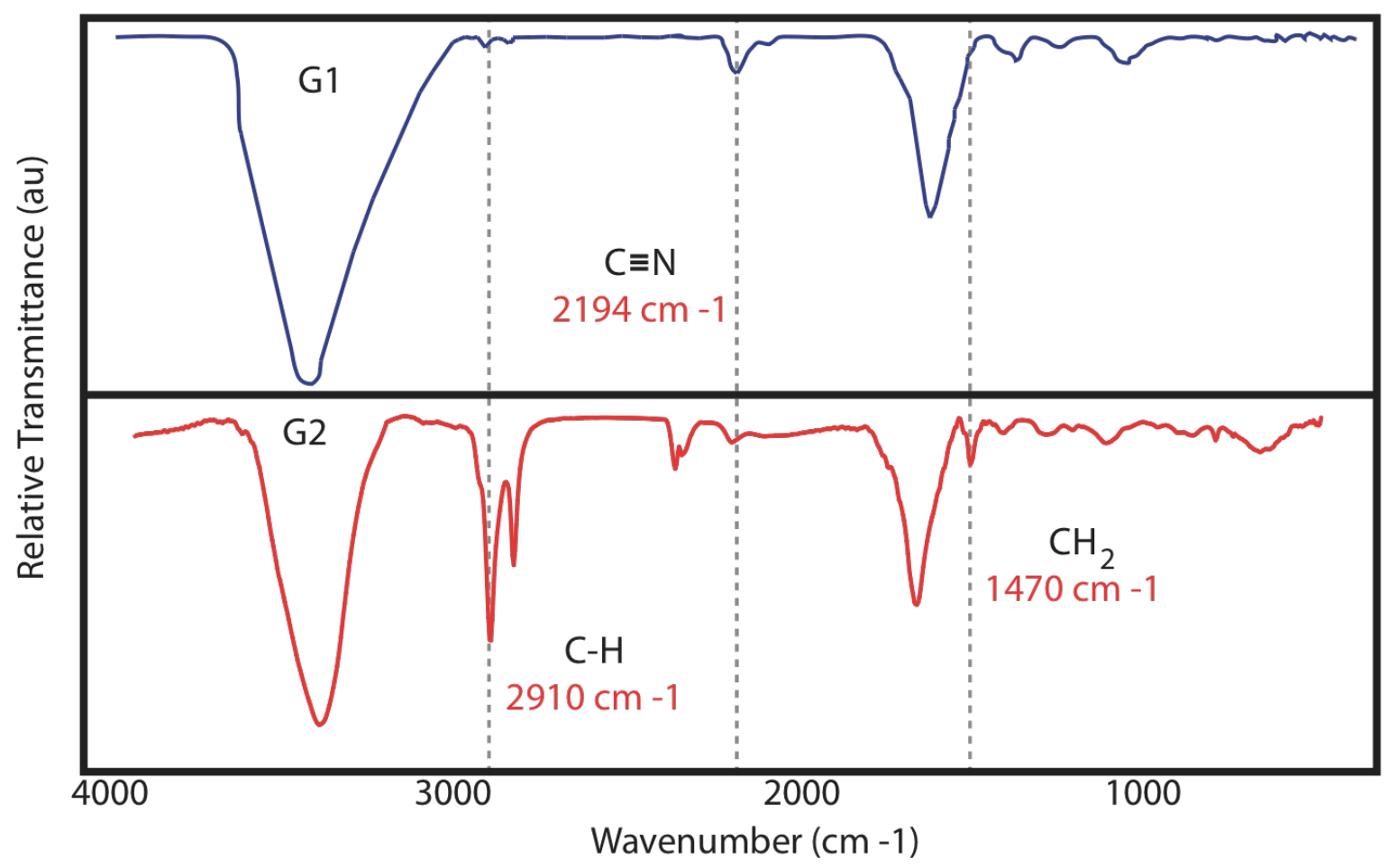

Figure S7. baseline corrected FT-IR spectra of malononitrile functionalized graphene (G1, blue) and hexadecane/malononitrile functionalized graphene $(\mathbf{G} 2$, red)

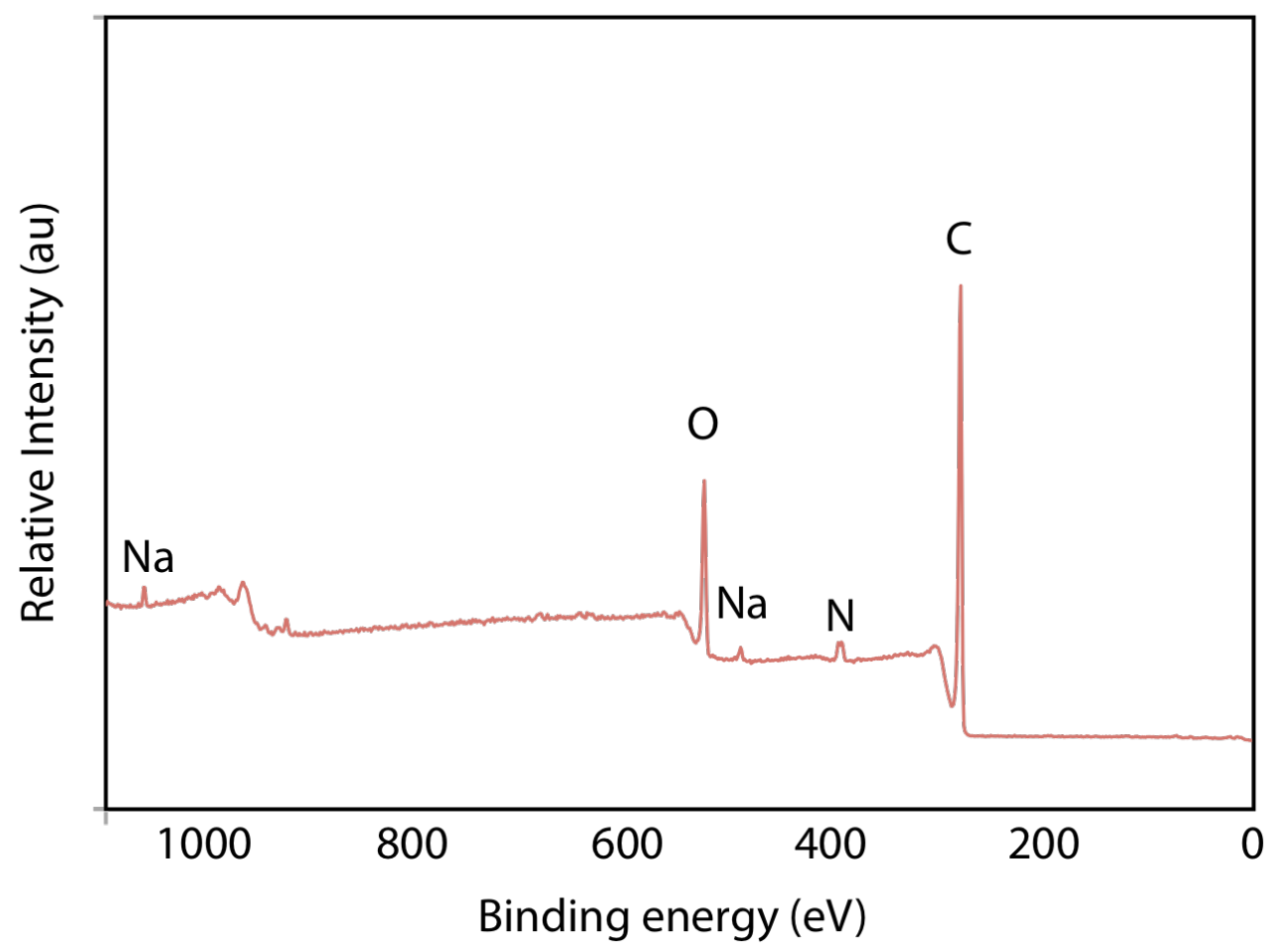

Figure S8. XPS survey spectrum of hexadecane graphene (G2, red), atomic \% composition [89.7\% $\mathrm{C} / 8.7 \% \mathrm{O} / 1.7 \% \mathrm{~N}]$ 


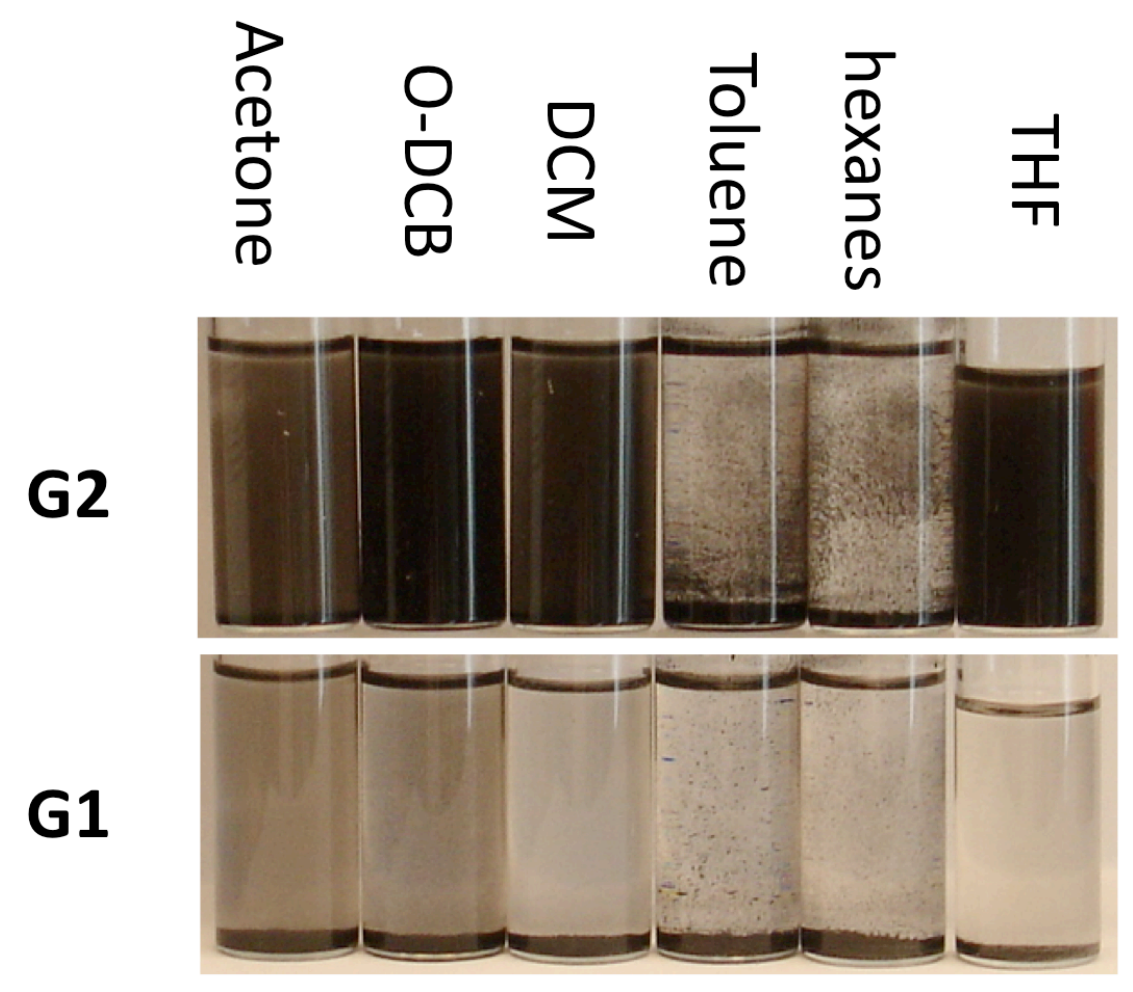

Figure S9. solubility profile of $\mathbf{G 2}(1 \mathrm{mg} / \mathrm{mL})$ and $\mathbf{G 1}(1 \mathrm{mg} / \mathrm{mL})$ in various solvents. Solutions were hand shaken for 30 seconds and allowed to sit for 5 minutes (no sonication).

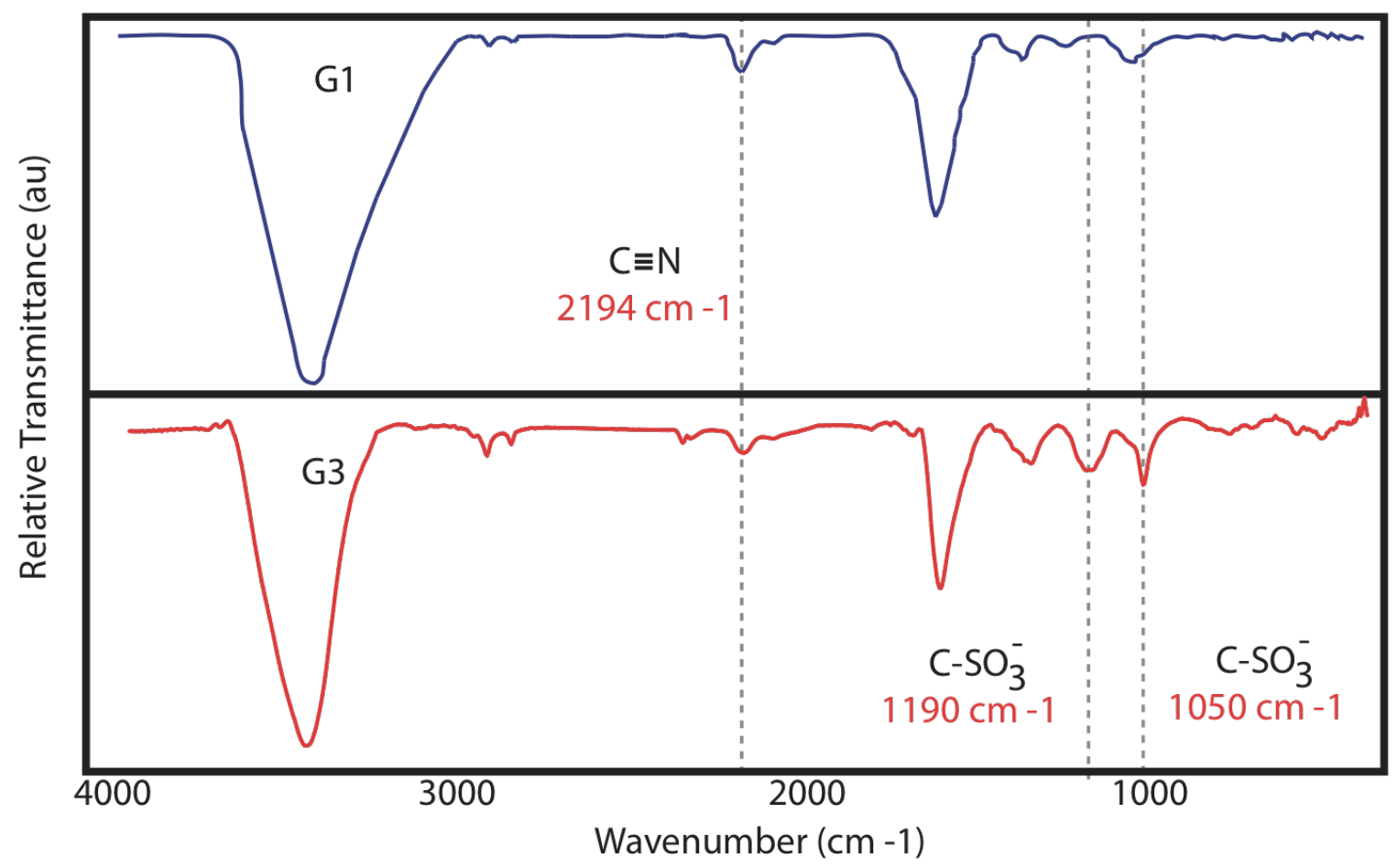

Figure S10. baseline corrected FT-IR spectra of malononitrile functionalized graphene (G1, blue) and sulfonate/malononitrile functionalized graphene $(\mathbf{G} 3$, red $)$ 


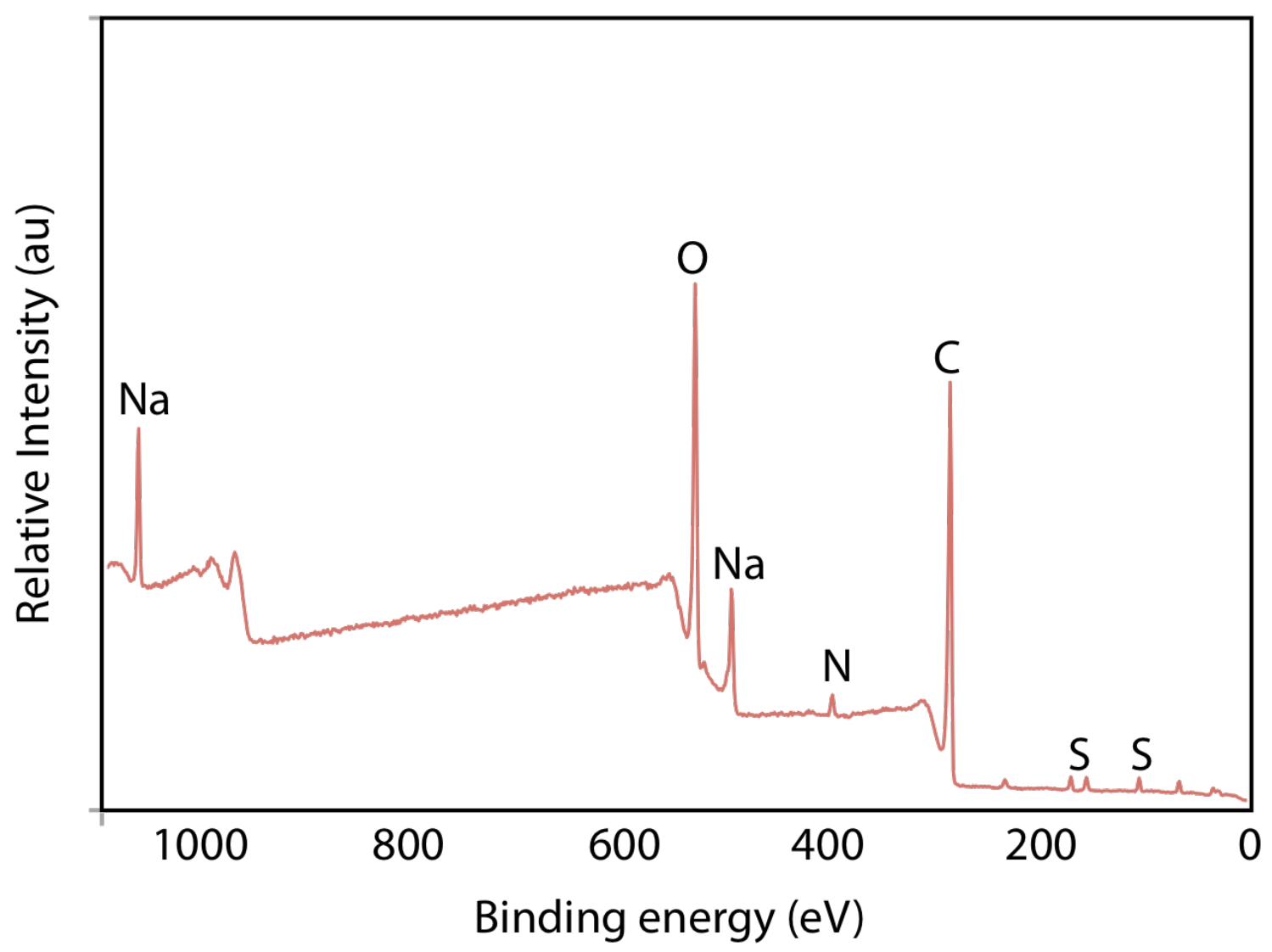

Figure S11. XPS survey spectrum of sulfonate graphene (G3, red), atomic \% composition [78\% $\mathrm{C} / 18.8 \% \mathrm{O} / 1.9 \% \mathrm{~N} / 1.3 \% \mathrm{~S}]$

\section{Citations:}

1 W. S. Hummers, R. E. Offeman, J. Amer. Chem. Soc. 1958, 80, 1339-1340.

2 Further attempts to increase the malononitrile functional group density by changing the reaction solvent and increasing the reaction temperature were unsuccessful. It is known that anionic malononitrile can begin to form oligomers or polymeric species at or above $130{ }^{\circ} \mathrm{C}$. This undesireable polymerization was observed experimentally in reactions of GO with anionic malononitrile at $150{ }^{\circ} \mathrm{C}$ in diglyme (as determined by $\sim 35 \%$ nitrogen incorporation by XPS).

3. Control reactions were performed by reacting GO with either 1-iodo hexadecane or the 1,3propane sultone in the presence of sodium hydride in THF at room temperature. After $24 \mathrm{~h}$ the reactions were cooled and the graphitic material completely sedimented. No noticeable changes occurred by FTIR and no improvements in solubility were observed in organic solvents for the hexadecane reaction, or in water for the sulfonate reaction.

3. L. J. Swartzendruber, National Bureau of Standards, 1964, Technical Note 199.

4. Attempts to completely remove the remaining sodium ions with additional washings had only a marginal effect (as determined by XPS analysis). The complete XPS report with sodium analysis is shown here: $\mathrm{C}(1 \mathrm{~s}) 79.25, \mathrm{O}(1 \mathrm{~s}) 14.68, \mathrm{~N}(1 \mathrm{~s}) 3.29, \mathrm{Na}(1 \mathrm{~s}) 2.79$. 